\title{
Promoter methylation status of the FHIT gene and Fhit expression: Association with HER2/neu status in breast cancer patients
}

\author{
YOUNG JU JEONG ${ }^{1}$, HYE YEON JEONG ${ }^{1}$, SANG MIN LEE $^{1}$, JIN GU BONG $^{1}$, \\ SUNG HWAN PARK ${ }^{1}$ and HOON KYU OH ${ }^{2}$
}

Departments of ${ }^{1}$ Surgery and ${ }^{2}$ Pathology, College of Medicine, Catholic University of Daegu, Daegu, Republic of Korea

Received June 18, 2013; Accepted July 30, 2013

DOI: $10.3892 / o r .2013 .2668$

\begin{abstract}
Aberrant DNA methylation has been recognized to contribute to breast carcinogenesis, and promoter hypermethylation of several tumor suppressor genes has been correlated with decreased gene expression. The fragile histidine triad (FHIT) gene is a putative tumor suppressor gene in breast and other types of cancer, and loss of Fhit expression has been observed in breast cancer. The aim of the present study was to evaluate the association between methylation of the FHIT gene and its expression in breast cancer, and to investigate whether methylation and expression of the FHIT gene correlates with clinicopathological characteristics in relation to human epidermal growth factor receptor 2 (HER2) status. Pyrosequencing of bisulfite-treated DNA was performed to study the methylation status of the FHIT gene in 60 breast cancer samples. We examined the expression of Fhit using tissue microarrays by immunohistochemical staining. FHIT methylation was detected in $96.7 \%$ and the positive expression rate of Fhit was $87.3 \%$ of the patients. The mean methylation level of the FHIT gene was associated with intratumoral inflammation. Methylation level of the FHIT gene had no significant differences according to molecular subtypes. Loss of Fhit expression was associated with large tumor size, basal-like subtype and positive expression of EGFR. In HER2negative breast cancer, loss of Fhit expression was significantly associated with tumor size, estrogen receptor status and Ki-67 proliferation index. No significant correlation between methylation of the FHIT gene and its expression was observed in the present study. Our results suggest that loss of Fhit expression in breast cancer is associated with poor prognostic features, and it is also relevant to the results in HER2-negative breast
\end{abstract}

Correspondence to: Professor Young Ju Jeong, Department of Surgery, College of Medicine, Catholic University of Daegu, 3056-6, Daemyoung-4-dong, Nam-gu, Daegu 705-718, Republic of Korea E-mail: yjjeong@cu.ac.kr

Key words: breast cancer, methylation, fragile histidine triad, human epidermal growth factor receptor 2, epigenetics cancer. Further studies with larger sample sizes and longer follow-up are required to clarify the predictive and prognostic value of Fhit expression and the FHIT gene methylation status in breast cancer.

\section{Introduction}

Breast carcinogenesis is a multi-step process characterized by tumor initiation and progression (1). There are well understood genetic and epigenetic alterations associated with breast carcinogenesis. Epigenetics is a heritable and reversible change in gene expression, and epigenetic alterations include DNA methylation and chromatin remodeling (2). DNA methylation occurs when methyl groups are added to cytosines in $\mathrm{CpG}$ dinucleotides resulting in the formation of methylcytosine (5-methylcytosine) and it leads to changes in chromatin structure and gene silencing (1-3). Several tumor suppressor genes contain $\mathrm{CpG}$ islands in their promoters, and a number of them show evidence of methylation silencing (3). Hypermethylation of regulatory regions of several tumor suppressor genes has been correlated with decreased gene expression, whereas hypomethylation of normally methylated tumor suppressor genes plays an important role in cancer development $(3,4)$. Gene specific epigenetic changes for breast cancer are likely to occur early in tumorigenesis and have the potential to be used for early detection and prevention (5). In particular, abnormal promoter region methylation in candidate tumor suppressor genes may be a useful biomarker by permitting early diagnosis and predicting the clinical behavior of the breast cancer.

The fragile histidine triad (FHIT) gene, encompassing the FRA3B fragile site at chromosome $3 \mathrm{p} 14.2$, is a tumor suppressor gene in several different types of cancer (6). The FHIT gene is a member of the histidine triad gene family, encoding a protein similar to the yeast diadenosine tetraphosphates hydrolase, which are intracellular and extracellular signaling molecules involved in cellular differentiation and apoptosis (6). In breast cancer, abnormalities at the FHIT locus have been demonstrated in considerably high frequency (7). These include loss of heterozygosity $(\mathrm{LOH})(8,9)$, homozygous deletions $(9,10)$, hypermethylation of the promoter region (11), abnormally sized transcripts (12) and reduced RNA and protein expression (13). 
Previous studies have shown that methylation is a mechanism of the FHIT gene inactivation in breast cancer $(11,14)$, and the FHIT gene promoter hypermethylation has been correlated with loss of gene expression in several different types of cancer, including breast cancer (15-19). Several studies (20-22) have evaluated the association between the FHIT gene hypermethylation and expression of Fhit protein encoded by the FHIT gene with clinicopathological characteristics in breast cancer, but with dissimilar results. There have been suggestions that DNA methylation profiles are associated with human epidermal growth factor receptor 2 (HER2) status of breast cancer (23) and Fhit cooperates with HER2 in breast carcinogenesis (24). However, limited information is available on the methylaton status of the FHIT gene and Fhit expression associated with HER2 status in breast cancer.

To further clarify the role of Fhit expression in breast cancer and its relation to gene hypermethylation, we evaluated the association between methylation of the FHIT gene and its expression in Korean breast cancer patients. We also investigated whether the FHIT gene methylation and expressions of Fhit correlate with clinicopathological characteristics in the same patients, specifically, according to HER2 status.

\section{Materials and methods}

Patients and materials. Formalin-fixed and paraffinembedded primary breast tumor tissue blocks from patients with breast cancer who underwent surgery at Daegu Catholic University Hospital (Daegu, South Korea) were examined. All specimens were reviewed by an experienced pathologist and a total of 60 sporadic invasive ductal carcinoma (IDC) tissue samples were included in the present study. The clinicopathological characteristics such as age, menopausal state, tumor size, nodal status, histologic grade, lymphovascular invasion, and prognostic factors including estrogen receptor (ER), progesterone receptor (PR), HER2, Bcl-2, Ki-67 and p53 expression were evaluated based on pathological reports and medical records. Pathological staging was assessed according to the seventh edition of the American Joint Committee on Cancer (AJCC) staging manual for breast cancer. We subclassified the breast cancer sample molecular subtypes into basal-like, HER2, luminal A, and luminal B subtypes according to immunohistochemical findings for the ER, PR, HER2 and Ki-67 proliferation index (25). Ethics approval for the study was obtained from the Institutional Review Board at the Daegu Catholic University Hospital.

Construction of tissue microarrays (TMA). Representative paraffin tumor blocks were selected according to the primary evaluation of hematoxylin and eosin (H\&E)-stained slides before they were prepared for TMA. Two tumor tissue cores ( $2 \mathrm{~mm}$ in diameter) were obtained from each of the donor breast cancer tissue blocks using a manual punch arrayer (Quick-Ray ${ }^{\mathrm{TM}}$; Uni-Tech Science, Seoul, South Korea). The cores were placed in a new recipient paraffin block that ultimately contained 50-60 tissue cores. Each array block contained both tumor and control tissue samples. Multiple sections ( $5 \mu \mathrm{m}$ thick) were cut from the TMA blocks and then mounted onto microscope slides. The TMA H\&E-stained sections were reviewed by light microscopy to confirm the presence of representative tumor areas.

Immunohistochemical staining and interpretation. Immunohistochemical analysis was performed on 5- $\mu$ m-thick TMA tissue sections using the Bond Polymer Intense Detection System (Leica Microsystems, Victoria, Australia) according to the manufacturer's instructions with minor modifications. Briefly, the 5- $\mu$ m-thick sections of formalin-fixed and paraffin-embedded TMA tissues were deparaffinized with Bond Dewax Solution (Leica Microsystems), and an antigen retrieval procedure was performed using Bond ER Solution (Leica Microsystems) for $30 \mathrm{~min}$ at $100^{\circ} \mathrm{C}$. The endogenous peroxidase was quenched by a 5 -min incubation with hydrogen peroxide. Sections were incubated for 15 min at ambient temperature with a rabbit polyclonal anti-Fhit antibody (ab53074, 1:150; Abcam, Cambridge, UK), and commercially available primary monoclonal antibodies for ER (1:100, clone $6 \mathrm{~F} 11$; Novocastra), PR (1:100, clone 16; Novocastra), HER2 (1:250, A0485; Dako), Ki-67 (1:200, MM1-L; Novocastra), Bcl-2 (1:4, clone 124; Dako), p53 (1:200, BP53.12; Zymed Laboratories), p16 (1:200; Dako, Denmark) and epidermal growth factor receptor (EGFR) (1:100, clone EGFR.25; Novocastra) using a biotin-free polymeric horseradish peroxidase-linker antibody conjugate system in a Bond-Max automatic slide stainer (Leica Microsystems).

Fhit expression levels were graded on a scale of 0 to $3+$ based on staining intensity and proportion of positive tumor cells by an expert pathologist who was blinded to the patient clinical records. The extent of positivity was scored as 0 , negative; $1+$, weak intensity, $<30 \%$ of cancer cells staining; $2+$, moderate intensity, 31-60\%; and 3+, strong intensity, $>60 \%$ (Fig. 1). For statistical analysis, diffuse absence of staining was regarded as negative expression, whereas any level of staining, regardless of percentage of cancer cell staining, was considered positive for Fhit expression.

A cut-off value of $10 \%$ for the stained nuclei was used to define ER and PR positivity. Cytoplasmic staining of any intensity in $>10 \%$ of the tumor cells was scored as positive for Bcl-2. Membranous staining for HER-2 with strong complete staining in $10 \%$ of the tumor cells was regarded as HER-2 overexpression. p53 and p16 staining was scored positive if $>10 \%$ of the cells were stained with a strong intensity. The Ki-67 labeling index was expressed as a percentage and was graded as 'high' if the number of positive cells was $\geq 14 \%$. Inflammation was assessed by scoring infiltration of mononuclear cells in the tumor cell nests and stroma (intratumoral) and adjacent stroma (peritumoral). The extent of lymphocyte infiltration was scored as 0 , no mononuclear cell infiltration; $1+$, focal scattered infiltration; $2+$, focal and clustered infiltration; and $3+$, diffuse infiltration and formation of lymphoid follicle. For statistical analysis, absence of mononuclear cell infiltration was defined as negative, and any level of mononuclear cell infiltration was considered positive for intratumoral or peritumoral inflammation.

DNA extraction and sodium bisulfate treatment. For DNA extraction, eight 5-10- $\mu \mathrm{m}$ thick tissue sections were obtained from paraffin-embedded primary breast cancer. Genomic DNA was isolated using QIAamp DNA FFPE Tissue kit (Qiagen, 


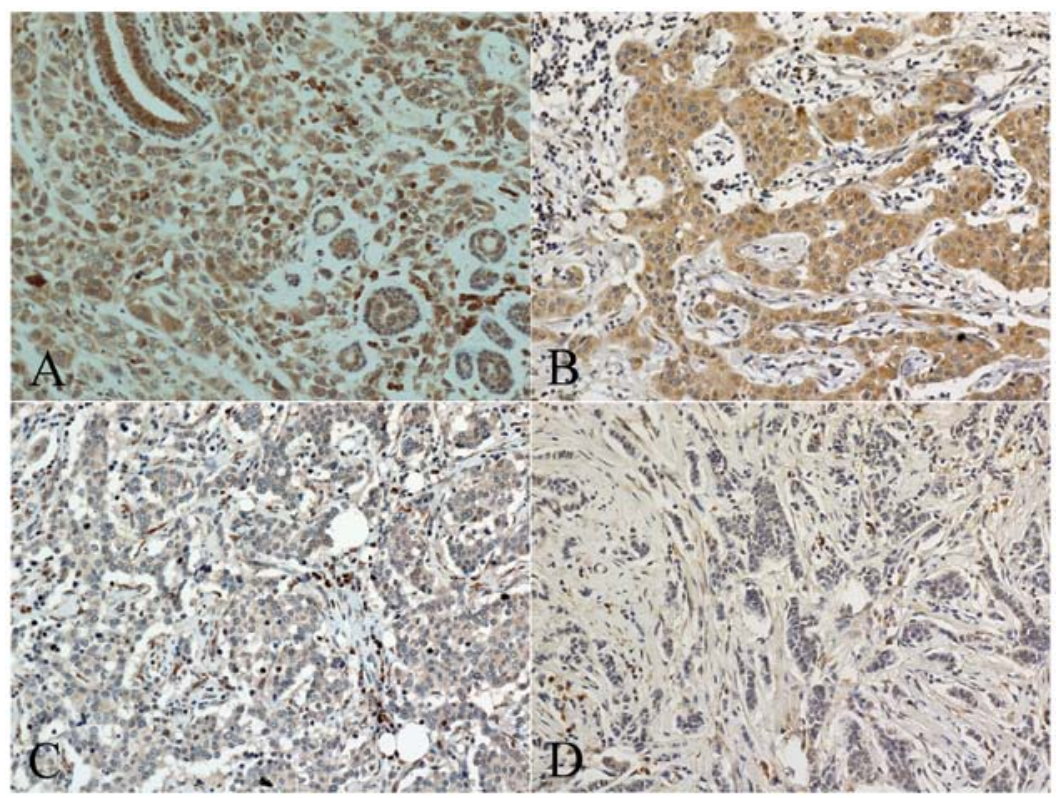

Figure 1. Immunohistochemical staining for Fhit in invasive ductal carcinoma of the breast. The Fhit expression represents strong (A), moderate (B), weak (C) and negative (D) immunoreactivity.

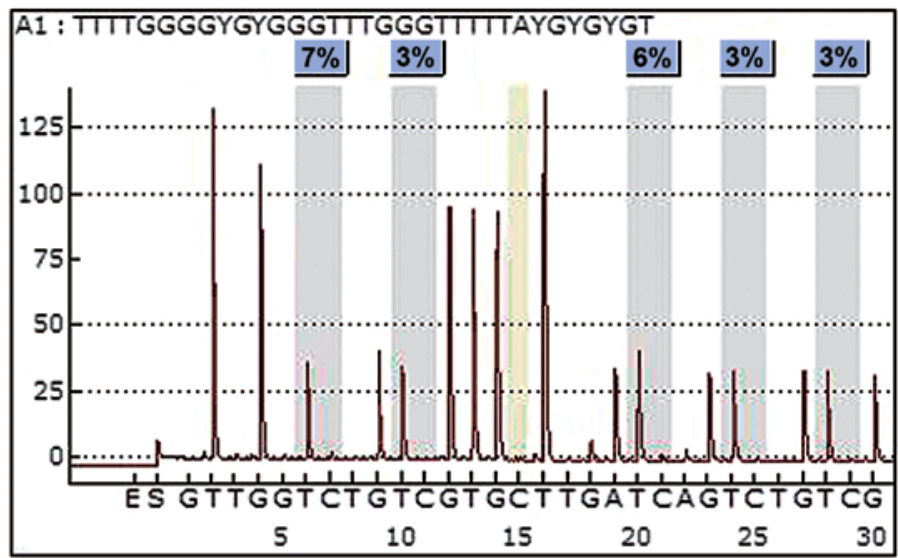

Figure 2. Partial pyrogram representing the methylation of the FHIT gene. Gray areas indicate the variable positions of CpG sites and quantitative CpG methylation levels are shown in a sequence context. By pyrosequencing, unmethylated cytosine, $C$ is measured as the relative content of $\mathrm{T}$ at the $\mathrm{CpG}$ site, and methylated cytosine, ${ }^{m} \mathrm{C}$, is measured as the relative content of $\mathrm{C}$ at the $\mathrm{CpG}$ site.

Hilden, Germany) by following the manufacturer's protocol. The purified DNA was quantified using an ND-1000 spectrophotometer (NanoDrop Technologies, Inc., Wilmington, DE, USA). The quality of the DNA was verified by performing gel electrophoresis. Sodium bisulfate modification of 200-500 ng genomic DNA was performed using the EZ DNA MethylationGold kit (Zymo Research, Orange, CA, USA) according to the manufacturer's protocol.

Pyrosequencing. Methylation was analyzed using pyrosequencing. Primer was designed using the PyroMark Assay Design program ver. 2.0.1.15 (Qiagen). For polymerase chain reaction (PCR), the forward primer was 5'-GGGAGGTAAGTT TAAGTGGAATATTG-3' and the reverse primer was 5'-CCACTAAACTCCCAAATAATAACCTAAC-3'. PCR was performed using bisulfate-treated DNA under the following conditions: $95^{\circ} \mathrm{C}$ for $5 \mathrm{~min} ; 45$ cycles of $95^{\circ} \mathrm{C}$ for
$30 \mathrm{sec}, 55^{\circ} \mathrm{C}$ for $30 \mathrm{sec}$ and $72^{\circ} \mathrm{C}$ for $30 \mathrm{sec}$; and final extension of $5 \mathrm{~min}$ at $72^{\circ} \mathrm{C}$. PCR was conducted using a PCR PreMix (Enzynomics, Daejeon, Korea) and the quality and quantity of the PCR product was confirmed by performing agarose gel (2\%) electrophoresis by loading $4 \mu \mathrm{l}$ of 20 PCR products. Pyrosequencing was performed using the Pyro Gold kit and PSQ 96 MA instrument (Qiagen) as instructed by the manufacturer. The Primer for DNA sequencing was 5'-GTAAGTTTAAGTGGAATATTGT-3'. The methylation index (MtI) of the FHIT gene in each sample was calculated as the average value of ${ }^{\mathrm{m}} C /\left({ }^{\mathrm{m}} \mathrm{C}+C\right)$ for all examined $\mathrm{CpGs}$ in target regions (Fig. 2). All experiments included a negative control without template.

Statistical analysis. Statistical analyses were performed using SPSS version 15.0 (SPSS, Inc., Chicago, IL, USA). A one-sample Kolmogorov-Smirnov test was used to evaluate 
Table I. Patient characteristics.

\begin{tabular}{|c|c|}
\hline Clinicopathological variables & Value \\
\hline Age (years), mean (range) & $51.77 \pm 13.22(26-90)$ \\
\hline \multicolumn{2}{|l|}{ Menopausal status, n (\%) } \\
\hline Pre-menopausal & $27(45.8)$ \\
\hline Post-menopausal & $32(54.2)$ \\
\hline Tumor size (cm), mean (range) & $1.80 \pm 0.93(0.10-4.50)$ \\
\hline \multicolumn{2}{|l|}{ Histological grade, $\mathrm{n}(\%)$} \\
\hline I & $13(21.7)$ \\
\hline II & $11(18.3)$ \\
\hline III & $36(60.0)$ \\
\hline \multicolumn{2}{|l|}{ Nodal involvement, $\mathrm{n}(\%)$} \\
\hline Negative & $40(69.0)$ \\
\hline Positive & $18(31.0)$ \\
\hline \multicolumn{2}{|l|}{ Distant metastasis, $\mathrm{n}(\%)$} \\
\hline Negative & $58(96.7)$ \\
\hline Positive & $2(3.3)$ \\
\hline \multicolumn{2}{|l|}{ Molecular subtype, n (\%) } \\
\hline Luminal A & $15(25.0)$ \\
\hline Luminal B & $15(25.0)$ \\
\hline HER2 & $15(25.0)$ \\
\hline Basal-like & $15(25.0)$ \\
\hline \multicolumn{2}{|l|}{ Lymphovascular invasion, n (\%) } \\
\hline Negative & $39(66.1)$ \\
\hline Positive & $20(33.9)$ \\
\hline \multicolumn{2}{|l|}{$\mathrm{ER}, \mathrm{n}(\%)$} \\
\hline Negative & $31(51.7)$ \\
\hline Positive & $29(48.3)$ \\
\hline \multicolumn{2}{|l|}{$\mathrm{PR}, \mathrm{n}(\%)$} \\
\hline Negative & $33(55.0)$ \\
\hline Positive & $27(45.0)$ \\
\hline \multicolumn{2}{|l|}{ HER 2 overexpression, n (\%) } \\
\hline Negative & $30(50.0)$ \\
\hline Positive & $30(50.0)$ \\
\hline \multicolumn{2}{|l|}{$\mathrm{Ki}-67, \mathrm{n}(\%)$} \\
\hline$<14$ & $25(41.7)$ \\
\hline$\geq 14$ & $35(58.3)$ \\
\hline $\begin{array}{l}\text { FHIT methylation frequency }(\%) \text {, } \\
\text { mean }\end{array}$ & $3.43 \pm 0.97$ \\
\hline \multicolumn{2}{|l|}{ Fhit expression, n (\%) } \\
\hline Negative & $7(12.8)$ \\
\hline Positive & $48(87.3)$ \\
\hline
\end{tabular}

HER2, human epidermal growth factor receptor 2; ER, estrogen receptor; PR, progesterone receptor; FHIT, fragile histidine triad.

the fitness to normal distribution of continuous parameters. Association between the methylation status of the FHIT gene and its expression was assessed using the Student's t-test or non-parametric Mann-Whitney U test. Associations between
Table II. Correlation between the FHIT gene methylation and its expression.

\begin{tabular}{lcc}
\hline & $\begin{array}{c}\text { FHIT methylation levels, } \\
\text { mean (\%) }\end{array}$ & P-value \\
\hline $\begin{array}{l}\text { Fhit expression } \\
\text { Positive } \\
\text { Negative }\end{array}$ & $3.41 \pm 1.01$ & 0.856 \\
& $3.49 \pm 0.74$ & \\
\hline
\end{tabular}

FHIT, fragile histidine triad.

the FHIT gene methylation status and the clinicopathological characteristics were assessed using the Student's t-test or the non-parametric Mann-Whitney $U$ test for categorical variables, and correlation between 2 continuous variables was assessed using correlation analysis. A comparison of the mean methylation level of the FHIT gene across the subtypes was performed using the ANOVA or the Kruskal-Wallis test. The relationship between the Fhit expression and the clinicopathological characteristics of the patients was analyzed using the Chi-square test or the Fisher's exact test for categorical data and the Student's t-test or the non-parametric Mann-Whitney U test for continuous data. Unconditional logistic regression was used to assess odds ratios (ORs) and 95\% confidence intervals (CIs). All tests were 2-sided and a P-value of $<0.05$ was considered to indicate a statistically significant difference.

\section{Results}

Clinicopathological characteristics. Clinical and pathological characteristics of patients are shown in Table I. The average age of the 60 patients with breast cancer was $51.77 \pm 13.22$ years (range, 26-90 years). Twenty-nine patients (48.3\%) were ER positive and 30 patients $(50.0 \%)$ were HER2 positive. Twenty-nine patients $(48.3 \%)$ had stage I disease, 21 patients $(35.0 \%)$ stage II, 6 patients $(10.0 \%)$ stage III and 4 patients $(6.7 \%)$ stage IV.

Methylation status of FHIT gene and its expression in breast cancer. Of the 60 patients studied, 58 patients $(96.7 \%)$ showed aberrant methylation of the FHIT gene in pyrosequencing analysis. The mean methylation level of the FHIT gene was $3.43 \pm 0.97 \%$. The methylation frequency of the FHIT gene showed no significant differences according to molecular subtypes of breast cancer $(\mathrm{P}=0.367)$.

Expression of Fhit protein was analyzed by immunohistochemical staining on breast cancer TMA from 60 invasive breast cancer cases. Some of the tissue specimens that were partly lost during TMA construction or were unavailable were excluded. According to the criteria for immunohistochemistry evaluation, positive Fhit expression was observed in 48/55 $(87.3 \%)$ primary breast tumor tissue samples.

To determine whether absence or decrease of Fhit expression in breast cancer correlates with the hypermethylation of the FHIT gene, we compared Fhit expression with the level of the FHIT gene methylation. Mean methylation level of the FHIT gene was 
Table III. Association of methylation levels of the FHIT gene and Fhit expression with clinicopathological characteristics.

\begin{tabular}{|c|c|c|c|c|}
\hline \multirow{2}{*}{$\begin{array}{l}\text { Clinicopathological } \\
\text { features }\end{array}$} & \multicolumn{2}{|c|}{ FHIT methylation } & \multicolumn{2}{|c|}{ Fhit expression } \\
\hline & Mean levels (\%) & P-value & Negative expression, n (\%) & P-value \\
\hline \multicolumn{5}{|l|}{ Age (years) } \\
\hline$<50$ & $3.25 \pm 0.81$ & \multirow[t]{2}{*}{0.149} & $4(14.8)$ & \multirow[t]{2}{*}{0.705} \\
\hline$\geq 50$ & $0.62 \pm 1.10$ & & $3(10.7)$ & \\
\hline \multicolumn{5}{|l|}{ Menopausal state } \\
\hline Pre-menopausal & $3.29 \pm 0.99$ & \multirow[t]{2}{*}{0.316} & $2(8.3)$ & \multirow[t]{2}{*}{0.443} \\
\hline Post-menopausal & $3.55 \pm 0.96$ & & $5(16.7)$ & \\
\hline \multicolumn{5}{|l|}{ Stage } \\
\hline I & $3.47 \pm 1.00$ & \multirow[t]{4}{*}{0.203} & $1(3.7)$ & \multirow[t]{4}{*}{0.244} \\
\hline II & $3.35 \pm 0.88$ & & $5(26.3)$ & \\
\hline III & $4.04 \pm 1.20$ & & $0(0.0)$ & \\
\hline IV & $2.73 \pm 0.61$ & & $1(33.3)$ & \\
\hline \multicolumn{5}{|l|}{ Tumor size $(\mathrm{cm})$} \\
\hline$\leq 2$ & $3.49 \pm 1.13$ & \multirow[t]{2}{*}{0.644} & $1(2.9)$ & \multirow[t]{2}{*}{0.006} \\
\hline$>2$ & $3.36 \pm 0.71$ & & $6(31.6)$ & \\
\hline \multicolumn{5}{|l|}{ Nodal involvement } \\
\hline Negative & $3.37 \pm 0.92$ & \multirow[t]{2}{*}{0.476} & $5(13.9)$ & \multirow[t]{2}{*}{0.651} \\
\hline Positive & $3.57 \pm 1.14$ & & $1(5.9)$ & \\
\hline \multicolumn{5}{|l|}{ Distant metastasis } \\
\hline Negative & $3.47 \pm 0.97$ & \multirow[t]{2}{*}{0.187} & $6(11.3)$ & \multirow[t]{2}{*}{0.240} \\
\hline Positive & $2.54 \pm 0.83$ & & $1(50.0)$ & \\
\hline \multicolumn{5}{|l|}{ Histological grade } \\
\hline $\mathrm{I}$ & $3.56 \pm 0.99$ & \multirow[t]{3}{*}{0.758} & $0(0.0)$ & \multirow[t]{3}{*}{0.204} \\
\hline II & $3.26 \pm 1.01$ & & $1(10.0)$ & \\
\hline III & $3.44 \pm 0.98$ & & $6(17.1)$ & \\
\hline \multicolumn{5}{|c|}{ Lymphovascular invasion } \\
\hline Negative & $3.41 \pm 0.91$ & 0.788 & $3(8.3)$ & 0.205 \\
\hline Positive & $3.48 \pm 1.13$ & & $4(22.2)$ & \\
\hline ER status & & & & \\
\hline Negative & $3.47 \pm 0.94$ & 0.768 & $6(20.7)$ & 0.105 \\
\hline Positive & $3.39 \pm 1.03$ & & $1(3.8)$ & \\
\hline PR status & & & & \\
\hline Negative & $3.53 \pm 0.83$ & 0.428 & $6(19.4)$ & 0.122 \\
\hline Positive & $3.32 \pm 1.13$ & & $1(4.2)$ & \\
\hline HER 2 overexpressio & & & & \\
\hline Negative & $3.35 \pm 0.87$ & 0.498 & $5(19.2)$ & 0.236 \\
\hline Positive & $3.52 \pm 1.09$ & & $2(6.9)$ & \\
\hline Molecular subtype & & & & \\
\hline Luminal A & $3.42 \pm 1.07$ & 0.367 & $0(0.0)$ & 0.036 \\
\hline Luminal B & $3.23 \pm 1.10$ & & $1(6.7)$ & \\
\hline HER2 & $3.82 \pm 1.02$ & & $1(7.1)$ & \\
\hline Basal-like & $3.28 \pm 0.62$ & & $5(35.7)$ & \\
\hline
\end{tabular}

FHIT, fragile histidine triad; ER, estrogen receptor; PR, progesterone receptor; HER2, human epidermal growth factor receptor 2.

slightly higher in the negative Fhit expression group (3.49\%) than that of the positive expression group (3.41\%); however, there was no significant correlation between methylation of the FHIT gene and its expression in the present study $(\mathrm{P}=0.856)$ (Table II). 
Table IV. Association of methylation levels of the FHIT gene and Fhit expression with other markers.

\begin{tabular}{|c|c|c|c|c|}
\hline \multirow[b]{2}{*}{ Variables } & \multicolumn{2}{|c|}{ FHIT methylation } & \multicolumn{2}{|c|}{ Fhit expression } \\
\hline & Mean levels (\%) & P-value & Negative expression, $\mathrm{n}(\%)$ & P-value \\
\hline \multicolumn{5}{|l|}{$\mathrm{Ki}-67$} \\
\hline$<14 \%$ & $3.39 \pm 0.93$ & 0.759 & $1(4.5)$ & 0.223 \\
\hline$\geq 14 \%$ & $3.47 \pm 1.02$ & & $6(18.2)$ & \\
\hline \multicolumn{5}{|l|}{ Bcl-2 } \\
\hline Negative & $3.46 \pm 1.01$ & 0.545 & $7(14.0)$ & 1.000 \\
\hline Positive & $3.18 \pm 0.48$ & & $0(0.0)$ & \\
\hline \multicolumn{5}{|l|}{ p53 } \\
\hline Negative & $3.50 \pm 0.98$ & 0.802 & $1(10.0)$ & 1.000 \\
\hline Positive & $3.42 \pm 0.98$ & & $6(13.3)$ & \\
\hline \multicolumn{5}{|l|}{ p16 } \\
\hline Negative & $3.45 \pm 0.98$ & 0.765 & $4(12.1)$ & 0.677 \\
\hline Positive & $3.36 \pm 1.08$ & & $3(17.6)$ & \\
\hline \multicolumn{5}{|l|}{ EGFR } \\
\hline Negative & $3.43 \pm 0.98$ & 0.858 & $1(3.1)$ & 0.036 \\
\hline Positive & $3.39 \pm 0.98$ & & $5(22.7)$ & \\
\hline \multicolumn{5}{|l|}{ Necrosis } \\
\hline Negative & $3.52 \pm 1.05$ & 0.715 & $2(6.9)$ & 0.210 \\
\hline Positive & $3.41 \pm 1.00$ & & $4(20.0)$ & \\
\hline \multicolumn{5}{|c|}{ Intratumoral inflammation } \\
\hline Negative & $2.89 \pm 0.40$ & 0.037 & $0(0.0)$ & 0.327 \\
\hline Positive & $3.62 \pm 1.06$ & & $6(15.0)$ & \\
\hline \multicolumn{5}{|c|}{ Peritumoral inflammation } \\
\hline Negative & $2.86 \pm 0.40$ & 0.083 & $0(0.0)$ & 1.000 \\
\hline Positive & $3.58 \pm 1.05$ & & $6(13.6)$ & \\
\hline
\end{tabular}

FHIT, fragile histidine triad; EGFR, epidermal growth factor receptor.

Relationship between methylation levels of the FHIT gene, the Fhit expression and the clinicopathological features. No significant correlation was found between the FHIT gene methylation levels and the clinicopathological features (Table III). Comparing the methylation levels of the FHIT gene with other markers, the FHIT gene methylation was significantly associated with intratumoral inflammation $(\mathrm{P}=0.037)$ (Table IV).

We correlated Fhit expression with clinicopathological features and other markers. The results showed that loss of Fhit expression was associated with large tumor size, basal-like subtype and positive expression of EGFR $(\mathrm{P}=0.003, \mathrm{P}=0.026$ and $\mathrm{P}=0.024$, respectively) (Tables III and IV). Loss of Fhit expression in EGFR-positive breast cancer correlated with tumor size $>2 \mathrm{~cm}(\mathrm{OR}=5.33,95 \% \mathrm{CI}, 1.92-14.79, \mathrm{P}=0.003)$. This was observed in ER-negative as well as in PR-negative cases $(\mathrm{OR}=3.14,95 \% \mathrm{CI}, 1.71-5.79, \mathrm{P}=0.005$ and $\mathrm{OR}=3.00$, $95 \% \mathrm{CI}, 1.70-5.28, \mathrm{P}=0.005$, respectively).

We stratified all cases by the HER2 status, and evaluated the relationship between loss of Fhit expression with clinicopathological features and other markers of breast cancer based on the HER2 status (Table V). Associations varied somewhat by HER2 status. For HER2-negative cases, loss of Fhit expression was significantly associated with tumor size, ER status and Ki-67 labeling index $(\mathrm{P}=0.005, \mathrm{P}=0.042$ and $\mathrm{P}=0.042$, respectively), whereas no significant correlation was found in HER2-positive cases.

\section{Discussion}

DNA hypermethylation is one of major epigenetic modifications and plays an important role in silencing tumor suppressor genes in all types of cancer, including breast cancer (2). The FHIT gene is a candidate tumor suppressor, and it has been postulated that the FHIT gene is involved in breast carcinogenesis $(6,7,9,10)$. 5' $\mathrm{CpG}$ island methylation of the FHIT gene has been investigated in breast cancer and it was demonstrated that methylation of the FHIT gene is a frequent event in breast cancer $(11,14)$. While qualitative analysis, specifically methylation-specific polymerase chain reaction, has been used in previous studies, the quantitative analysis of methylation has rarely been studied. We quantitatively analyzed the promoter methylation status of the FHIT gene in primary breast cancer by using pyrosequencing. In the present study, $96.7 \%$ of the 
Table V. Association of loss of Fhit expression with clinicopathological features in HER2-positive and -negative breast cancer patients.

\begin{tabular}{|c|c|c|c|c|c|c|}
\hline & \multicolumn{3}{|c|}{ HER2-positive } & \multicolumn{3}{|c|}{ HER2-negative } \\
\hline & $\begin{array}{c}\text { Loss of Fhit } \\
\text { expression, } \mathrm{n}(\%)\end{array}$ & OR $(95 \% \mathrm{CI})$ & P-value & $\begin{array}{c}\text { Loss of Fhit } \\
\text { expression, n (\%) }\end{array}$ & OR $(95 \% \mathrm{CI})$ & P-value \\
\hline \multicolumn{7}{|l|}{ Stage } \\
\hline $\mathrm{I}$ & $1(5.9)$ & & 1.000 & $0(0.0)$ & & 0.081 \\
\hline II & $1(14.3)$ & & & $4(33.3)$ & & \\
\hline III & $0(0.0)$ & & & $0(0.0)$ & & \\
\hline IV & $0(0.0)$ & & & $1(100.0)$ & & \\
\hline \multicolumn{7}{|c|}{ Tumor size (cm) } \\
\hline$\leq 2$ & $1(5.0)$ & $0.711(0.174-2.903)$ & 0.532 & $0(0.0)$ & & 0.005 \\
\hline$>2$ & $1(11.1)$ & $1.688(0.375-7.585)$ & & $5(50.0)$ & $4.000(1.872-8.545)$ & \\
\hline \multicolumn{7}{|c|}{ Nodal involvement } \\
\hline Negative & $2(9.5)$ & $1.368(1.084-1.728)$ & 1.000 & $3(20.0)$ & $1.313(0.667-2.581)$ & 0.626 \\
\hline Positive & $0(0.0)$ & & & $1(10.0)$ & $0.583(0.100-3.417)$ & \\
\hline \multicolumn{7}{|c|}{ Distant metastasis } \\
\hline Negative & $2(7.1)$ & $1.038(0.964-1.118)$ & 1.000 & $4(16.0)$ & $0.800(0.516-1.240)$ & 0.192 \\
\hline Positive & $0(0.0)$ & & & $1(100.0)$ & & \\
\hline \multicolumn{7}{|c|}{ Histological grade } \\
\hline I & $0(0.0)$ & & 1.000 & $0(0.0)$ & & 0.061 \\
\hline II & $1(16.7)$ & & & $0(0.0)$ & & \\
\hline III & $1(5.0)$ & & & $5(33.3)$ & & \\
\hline \multicolumn{7}{|c|}{$\begin{array}{l}\text { Lymphovascular } \\
\text { invasion }\end{array}$} \\
\hline Negative & $1(5.0)$ & $0.711(0.174-2.903)$ & 0.532 & $2(12.5)$ & $0.571(0.188-1.736)$ & 0.312 \\
\hline Positive & $1(11.1)$ & $1.688(0.375-7.585)$ & & $3(33.3)$ & $2.000(0.751-5.329)$ & \\
\hline \multicolumn{7}{|l|}{ ER status } \\
\hline Negative & $1(6.7)$ & $0.964(0.230-4.041)$ & 1.000 & $5(35.7)$ & $2.333(1.424-3.823)$ & 0.042 \\
\hline Positive & $1(7.1)$ & $1.038(0.246-4.384)$ & & $0(0.0)$ & & \\
\hline \multicolumn{7}{|l|}{ PR status } \\
\hline Negative & $1(6.3)$ & $0.900(0.216-3.747)$ & 1.000 & $5(33.3)$ & $2.100(1.341-3.289)$ & 0.053 \\
\hline Positive & $1(7.7)$ & $1.125(0.264-4.790)$ & & $0(0.0)$ & & \\
\hline \multicolumn{7}{|l|}{ Ki-67 } \\
\hline$<14 \%$ & $1(10.0)$ & $1.500(0.340-6.623)$ & 1.000 & $0(0.0)$ & & 0.042 \\
\hline$\geq 14 \%$ & $1(5.3)$ & $0.750(0.183-3.076)$ & & $5(35.7)$ & $2.333(1.424-3.823)$ & \\
\hline \multicolumn{7}{|l|}{ Bcl-2 } \\
\hline Negative & $2(7.4)$ & $1.080(0.971-1.202)$ & 1.000 & $5(21.7)$ & $1.167(0.980-1.389)$ & 1.000 \\
\hline Positive & $0(0.0)$ & & & $0(0.0)$ & & \\
\hline \multicolumn{7}{|l|}{$\mathrm{p} 53$} \\
\hline Negative & $0(0.0)$ & & 1.000 & $1(16.7)$ & $0.840(0.124-5.688)$ & 1.000 \\
\hline Positive & $2(8.0)$ & $1.174(1.003-1.374)$ & & $4(20.0)$ & $1.050(0.637-1.730)$ & \\
\hline \multicolumn{7}{|l|}{ p16 } \\
\hline Negative & $2(10.5)$ & $1.588(1.189-2.121)$ & 0.532 & $2(14.3)$ & $0.533(0.176-1.619)$ & 0.280 \\
\hline Positive & $0(0.0)$ & & & $3(42.9)$ & $2.400(0.791-7.284)$ & \\
\hline \multicolumn{7}{|l|}{ EGFR } \\
\hline Negative & $1(4.8)$ & $1.350(1.080-1.688)$ & 1.000 & $0(0.0)$ & & 0.053 \\
\hline Positive & $0(0.0)$ & & & $5(33.3)$ & $2.100(1.341-3.289)$ & \\
\hline
\end{tabular}

FHIT, fragile histidine triad; HER2, human epidermal growth factor receptor 2; OR, odds ratio; CI, confidence interval; ER, estrogen receptor; PR, progesterone receptor; EGFR, epidermal growth factor receptor. 
breast cancer cases had an aberrant methylation of the FHIT gene and the result reveals that methylation is one of the major mechanisms in the regulation of the FHIT gene.

Several studies showed that loss of Fhit expression was significantly correlated with methylation status of the FHIT gene $(11,20)$. On the other hand, Yang et al (22) did not find a significant correlation between the FHIT gene methylation and Fhit expression, which is consistent with our results. There are several mechanisms besides hypermethylation by which reduced Fhit expression can occur, such as $\mathrm{LOH}(8,9,22)$, homozygous deletions $(9,10)$, abnormal transcripts $(12)$, and reduced mRNA expression (13). In addition, Syeed et al (21) showed the mutations of the FHIT gene in breast cancer that lead to the reduced expression level of Fhit. We did not find any association between the FHIT gene methylation and Fhit expression. Another possible complicated mechanism for loss of Fhit expression in breast cancer has been reported (6), however, it is not included in the present study.

The HER2 gene encoding a transmembrane glycoprotein that is a member of the EGFR family, is amplified and overexpressed in 20-30\% of invasive breast carcinomas (26). A recent study showed an association between HER2 status and DNA methylation profiles of breast cancer, and suggested that differences in DNA methylation profile reflect the higher aggressiveness of HER2-positive breast cancer (23). However, in the present study, we did not find an association between methylation status of the FHIT gene and HER2 status. Several studies have shown that downregulation of Fhit protein levels not due to promoter hypermethylation but to Fhit protein posttranslational modification $(24,27)$, and they demonstrated the association between Fhit expression and HER2 status in breast cancer. Bianchi et al analyzed the impact of Fhit downregulation due to EGFR family activation in human breast tumor development and progression (29), and showed that Fhit protein levels can be regulated by Fhit proteasome degradation mediated by EGF-dependent activation of EGFR family members, including HER2 (27). In the present study, we showed that Fhit expression does not correlate with HER2 overexpression. However, when stratifying the cases by HER2 status, loss of Fhit expression was associated with poor prognostic markers such as large tumor size, negative ER status and high Ki-67 labeling index. Our results suggest crossregulation between HER2 overexpression and loss of Fhit expression in breast cancer, which is relevant to the results of a previous study (29).

It has been postulated that aberrant Fhit expression is associated with pathogenesis and prognostic markers in breast cancer (12,14,30-32). Research on the FHIT gene has demonstrated that Fhit interacts with different proteins through different pathways (6). Although the exact clinicopathological significance of loss of Fhit expression in breast cancer is not known, several studies have indicated that it is associated with increased tumor size (30), increased histological grade, ER negativity, increased tumor proliferation index, increased p53 expression, increased expression of Ki-67 and decreased expression of Bcl-2 (31). In our study, we correlated the expression of Fhit with clinocopathological characteristics as well as other prognostic markers. Loss of Fhit expression was correlated with poor prognostic markers such as large tumor size, basal-like subtype and positive expression of EGFR.
Estrogen has been implicated in the etiology of breast cancer (33) and hormone receptor (HR) status, defined as ER and/or PR status, have been used as prognostic markers in breast cancer. Recent advances in molecular profiling and DNA methylation analysis have suggested DNA-based surrogate markers for expression status (34). Methylation in breast cancer has been linked to the hormone regulation. Previous studies showed that gene expression profiles were different according to the HR status of breast cancer $(35,36)$, and other studies suggested that DNA methylation profiles of breast cancer are associated with HR biology $(29,37)$. However, in the present study, we did not find an association between methylation status of the FHIT gene and HR status. When stratifying the cases by HR status, there was no association between methylation status of the FHIT gene and clinicopathological features, whereas loss of Fhit expression was associated with large tumor size in ER-negative as well as PR-negative cases.

To the best of our knowledge, the present study is the first report that quantitatively analyzed the promoter methylation status of the FHIT gene by using pyrosequencing in primary breast cancer and correlated the quantitative data on the levels of the FHIT gene methylation with its protein expression. Pyrosequencing analysis can provide reproducible measurements of average methylation levels in sequential $\mathrm{CpG}$ sites, thus, this method is rapid and accurate (38). On the other hand, limitations of our study include relatively small number of sample size and absence of control group, including normal or benign breast tissue. In addition, we did not perform survival analysis due to short follow-up period. Further studies in larger cohorts with longer follow-up are required to clarify the predictive and prognostic value of the FHIT gene methylation and Fhit expression in breast cancer.

In conclusion, our study revealed that loss of Fhit expression in breast cancer is associated with poor prognostic features, although there is no significant association between the FHIT gene methylation and Fhit expression. We found that in HER2-negative breast cancer, loss of Fhit expression was associated with poor prognostic features. These results support the possibility of potential complementation between HER2 and the Fhit pathway (29). The clinical significance of our findings requires further evaluation in larger cohorts with longer follow-up.

\section{Acknowledgements}

The present study was supported by research grants from the Catholic University of Daegu in 2011.

\section{References}

1. Dworkin AM, Huang TH and Toland AE: Epigenetic alterations in the breast: implications for breast cancer detection, prognosis and treatment. Semin Cancer Biol 19: 165-171, 2009.

2. Hinshelwood RA and Clark SJ: Breast cancer epigenetics: normal human mammary epithelial cells as a model system. J Mol Med 86: 1315-1328, 2008.

3. Widschwendter M and Jones PA: DNA methylation and breast carcinogenesis. Oncogene 21: 5462-5482, 2002.

4. Pogribny IP and Beland FA: DNA hypomethylation in the origin and pathogenesis of human diseases. Cell Mil Life Sci 66: 2249-2261,2009. 
5. Balch C, Montgomery JS, Paik HI, et al: New anti-cancer strategies: epigenetic therapies and biomarkers. Front Biosci 10: 1897-1931, 2005.

6. Wali A: FHIT: Doubts are clear now. Sci World J 10: 1142-1151, 2010.

7. Ingvarsson S: FHIT alterations in breast cancer. Semin Cancer Biol 11: 361-366, 2001.

8. Ingvarsson S, Sigbjornsdottir BI, Huiping C, Jonasson JG and Agnarsson BA: Alterations of the FHIT gene in breast cancer: association with tumour progression and patient survival. Cancer Detect Prev 25: 292-298, 2001.

9. Ahmadian M, Wistuba II, Fong KM, et al: Analysis of the FHIT gene and FRA3B region in sporadic breast cancer, preneoplastic lesions, and familial breast cancer probands. Cancer Res 57: 3664-3668, 1997.

10. Negrini M, Monaco G, Vorchovsky I, et al: The FHIT gene at 3p14.2 is abnormal in breast carcinomas. Cancer Res 56 3173-3179, 1996.

11. Zöchbauer-Müller S, Fong KM, Maitra A, et al: 5' CpG island methylation of the FHIT gene is correlated with loss of gene expression in lung and breast cancer. Cancer Res 61: 3581-3585, 2001.

12. Hayashi S, Tanimoto K, Hajiro-Nakanishi K, et al: Abnormal FHIT transcripts in human breast carcinomas: a clinicopathological and epidemiological analysis of 61 Japanese cases. Cance Res 57: 1981-1985, 1997.

13. Ingvarsson S, Agnarsson BA, Sigbjornsdottir BI, et al: Reduced Fhit expression in sporadic and BRCA2-linked breast carcinomas. Cancer Res 59: 2682-2689, 1999.

14. Gatalica Z, Lele SM, Rampy BA and Norris BA: The expression of Fhit protein is related inversely to disease progression in patients with breast carcinoma. Cancer 88: 1378-1383, 2000.

15. Naqvi RA, Hussain A, Raish M, et al: Specific 5' CpG island methylation signatures of FHIT and p16 genes and their potential diagnostic relevance in Indian breast cancer patients. DNA Cell Biol 27: 517-525, 2008

16. Maruyama R, Toyooka S, Toyooka KO, et al: Aberrant promoter methylation profile of bladder cancer and its relationship to clinicopathological features. Cancer Res 61: 8659-8663, 2001.

17. Maruyama R, Toyooka S, Toyooka KO, et al: Aberrant promoter methylation profile of prostate cancers and its relationship to clinicopathological features. Clin Cancer Res 8 : 514-519, 2002

18. Virmani AK, Muller C, Rathi A, Zoechbauer-Mueller S, Mathis M and Gazdar AF: Aberrant methylation during cervical carcinogenesis. Clin Cancer Res 7: 584-589, 2001.

19. Kim H, Kwon YM, Kim JS, et al: Tumor-specific methylation in bronchial lavage for early detection on non-small cell lung cancer. J Clin Oncol 22: 2363-2370, 2004.

20. Raish M, Dhillon VS, Ahmad A, et al: Promoter hypermethylation in tumor suppressing genes p16 and FHIT and their relationship with estrogen receptor and progesterone receptor status in breast cancer patients from Northern India. Trans Onco 2: 264-270, 2009.

21. Syeed N, Husain SA, Sameer AS, Chowdhri NA and Siddiqi MA Mutational and promoter hypermethylation status of FHIT gene in breast cancer patients of Kashmir. Mutation Res 707: 1-8, 2011.
22. Yang Q, Nakamura M, Nakamura Y, et al: Two-hit inactivation of FHIT by loss of heterozygosity and hypermethylation in breast cancer. Clin Cancer Res 8: 2890-2893, 2002.

23. Fiegl H, Millinger S, Goebel G, et al: Breast cancer DNA methylation profiles in cancer cells and tumor stroma: association with HER-2/neu status in primary breast cancer. Cancer Res 66 29-33, 2006.

24. Bianchi F, Magnifico A, Olgiati C, et al: FHIT-proteasome degradation caused by mitogenic stimulation of the EGF receptor family in cancer cells. Proc Natl Acad Sci USA 103: 18981-18986, 2006.

25. Goldhirsch A, Wood WC, Coates AS, et al: Strategies for subtypes - dealing with the diversity of breast cancer: highlights of the St. Gallen International Expert Consensus on the Primary Therapy of Early Breast Cancer 2011. Ann Oncol 22: 1736-1747, 2011.

26. Menard S, Tagliabue E, Campiglio M and Pupa SM: Role of HER2 gene overexpression in breast carcinoma. J Cell Physiol 182: 150-162, 2000.

27. Pekarsky Y, Garrison PN, Palamarchuk A, et al: Fhit is a physiological target of the protein kinase Src. Proc Natl Acad Sci USA 101: 3775-3779, 2004.

28. Campan M, Weisenberger DJ and Laird PW: DNA methylation profiles of female steroid hormone-driven human malignancies. Curr Top Microbiol Immunol 310: 141-178, 2006.

29. Bianchi F, Tagliabue E, Ménard S and Campiglio M: Fhit expression protects against HER2-driven breast tumor development. Cell Cycle 6: 643-646, 2007.

30. Campiglio M, Pekarsky Y, Menard S, Tagliabue E, Pilotti S and Croce CM: FHIT loss of function in human primary breast cancer correlates with advanced stage of the disease. Cancer Res 59: 3866-3869, 1999.

31. Yang Q, Yoshimura G, Suzuma T, et al: Clinicopathological significance of fragile histidine triad transcription protein expression in breast carcinoma. Clin Cancer Res 7: 3869-3873, 2001.

32. Arun B, Kilic G, Yen C, et al: Loss of FHIT expression in breast cancer is correlated with poor prognostic markers. Cancer Epidemiol Biomarkers Prev 14: 1681-1685, 2005.

33. Key TJ and Pike MC: The role of oestrogens and progestagens in the epidemiology and prevention of breast cancer. Eur J Cancer Clin Oncol 24: 29-43, 1988.

34. Jones PA and Baylin SB: The fundamental role of epigenetic events in cancer. Nat Rev Genet 3: 415-428, 2002.

35. Creighton CJ, Kent Osborne C, van de Vijver MJ, et al: Molecular profiles of progesterone receptor loss in human breast tumors. Breast Cancer Res Treat 114: 287-299, 2009.

36. Li L, Lee KM, Ha W, et al: Estrogen and progesterone receptor status affect genome-wide DNA methylation profile in breast cancer. Hum Mol Genet 19: 4273-4277, 2010.

37. Widschwendter M, Siegmund KD, Muller HM, et al: Association of breast cancer DNA methylation profiles with hormone receptor status and response to tamoxifen. Cancer Res 64: 3807-3813, 2004.

38 Tost J and Gut IG: Analysis of gene-specific DNA methylation patterns by pyrosequencing technology. Methods Mol Biol 373: 89-102, 2007. 